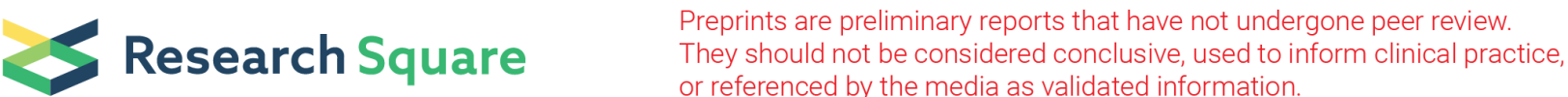

\section{Inkjet-Printed Wide Range and Highly Linear Signal Processed Systematic Humidity Sensor Array Based on Methylene Blue and Graphene Nanocomposite}

Muhammad Umair Khan

Jeju National University

Gul Hassan

International Islamic University

Rayyan Ali Shaukat

Jeju National University

Qazi Muhammad Saqib

Jeju National University

Mahesh Chougale

Jeju National University

Jungmin Kim

Jeju National University

Jinho Bae ( $\sim$ baejh@jejunu.ac.kr)

Jeju National University

\section{Research Article}

Keywords: Humidity sensor array, graphene with different particle sizes, Methylene Blue, graphene flakes, graphene quantum dots, Interdigital electrode

Posted Date: December 21st, 2020

DOl: https://doi.org/10.21203/rs.3.rs-131189/v1

License: (c) (1) This work is licensed under a Creative Commons Attribution 4.0 International License.

Read Full License

Version of Record: A version of this preprint was published at Scientific Reports on August 17th, 2021. See the published version at https://doi.org/10.1038/s41598-021-95977-6. 


\section{Abstract}

This paper proposes a signal processed systematic humidity sensor $3 \times 3$ array with all range and highly linear humidity response based on different particle size nanocomposite inks and different interspaces of interdigital electrodes (IDEs) $(300,200$, and $100 \mu \mathrm{m})$. The fabricated sensors are patterned through a commercial inkjet printer by utilizing nanocomposites of methylene blue and graphene with three different particle sizes of bulk Graphene Flakes (BGF), Graphene Flakes (GF), and Graphene Quantum Dots (GQD), which are employed as an active layer on three types of IDEs with different interspaces of 300,200 , and $100 \mu \mathrm{m}$. From $3 \times 3$ sensor array, all range linear function $(0-100 \% \mathrm{RH})$ is achieved by applying linear combination method of nine sensors in signal processing field, where weights for linear combination are required, which are estimated by the least square solution. The humidity sensing array shows a fast response time ( $\left.T_{\text {res }}\right)$ of $0.2 \mathrm{sec}$ and recovery time $\left(T_{\text {rec }}\right)$ of $0.4 \mathrm{sec}$. From the results, the proposed humidity sensor array opens a new gateway for a wide range of humidity sensing applications with a linear function.

\section{Full Text}

This preprint is available for download as a PDF.

\section{Figures}




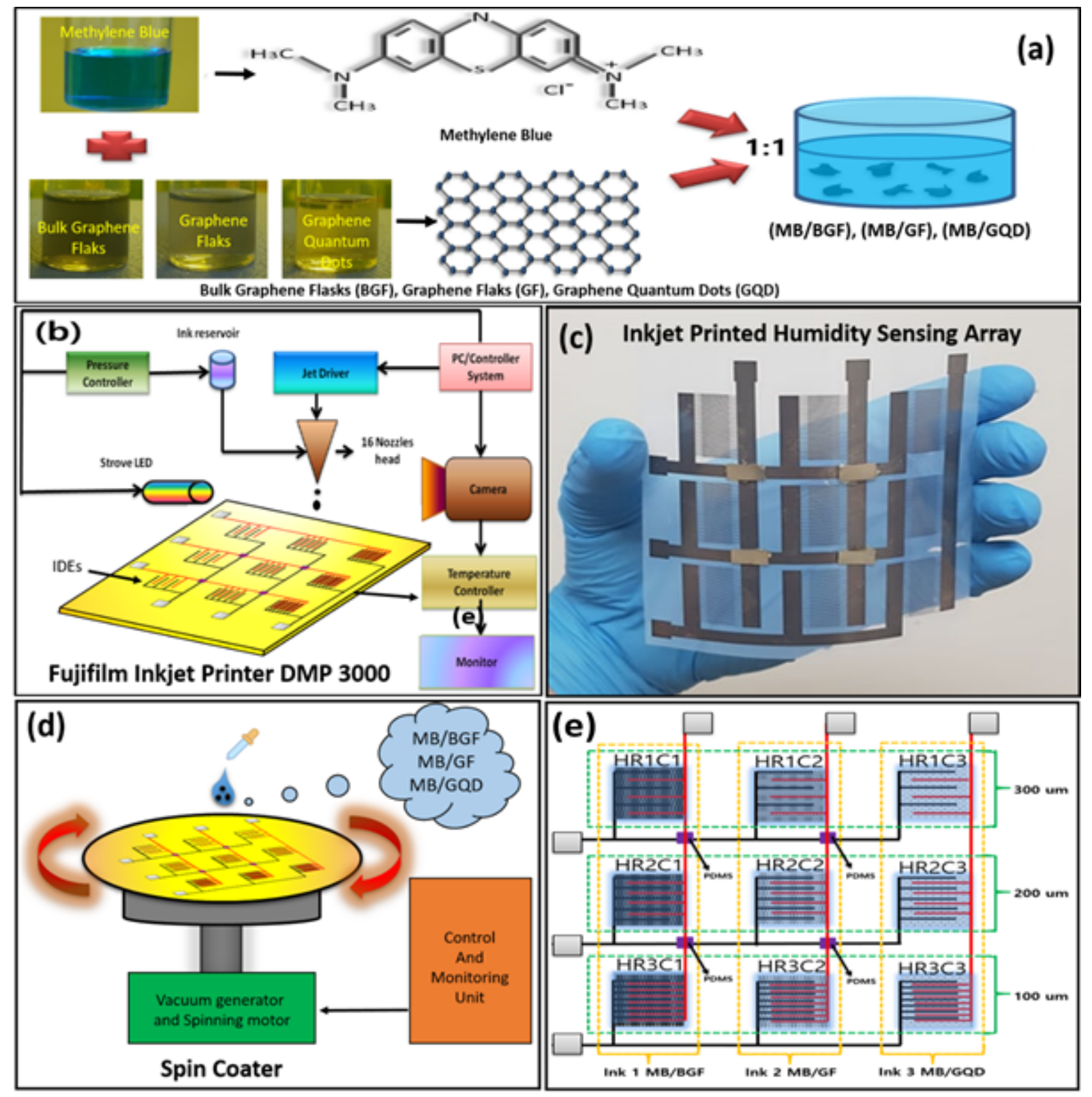

Figure 1

(a) The ink preparation of graphene different particles size with MB. (b) Fabrication IDEs $3 \times 3$ humidity sensor array using the DMP-3000 inkjet printer. (c) Realized image of the fabricated sensor array. (d) Fabrication of the sensing active layer using a spin coater. (e) Fabricated $3 \times 3$ humidity sensor array showing IDEs spacing and coated ink on each column. 


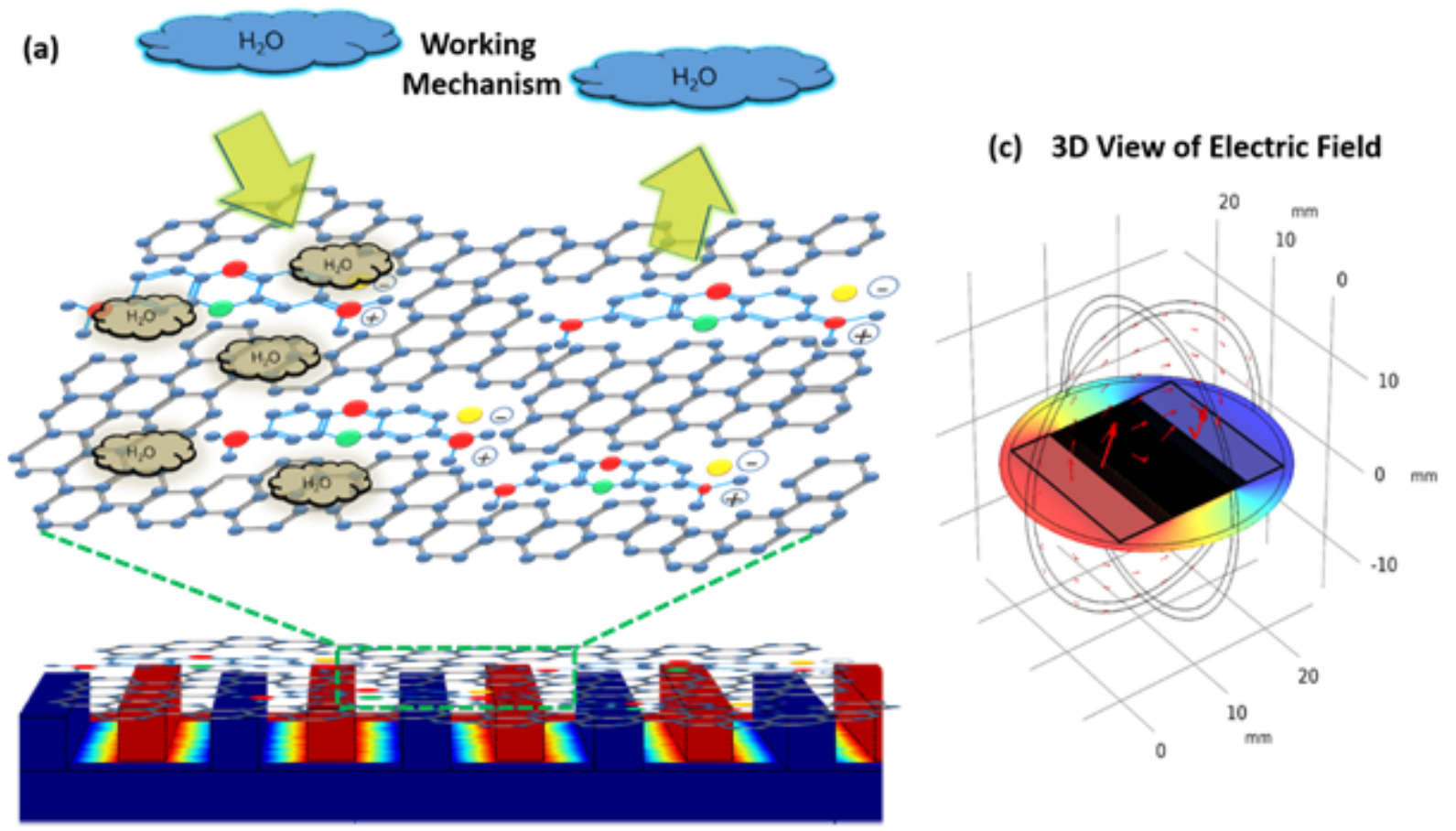

(b) Cross-sectional Electric potential View

Figure 2

(a) Sensing mechanism, (b) cross-sectional view of the electric potential applied on IDEs, and (c) 3D view of an electric field.

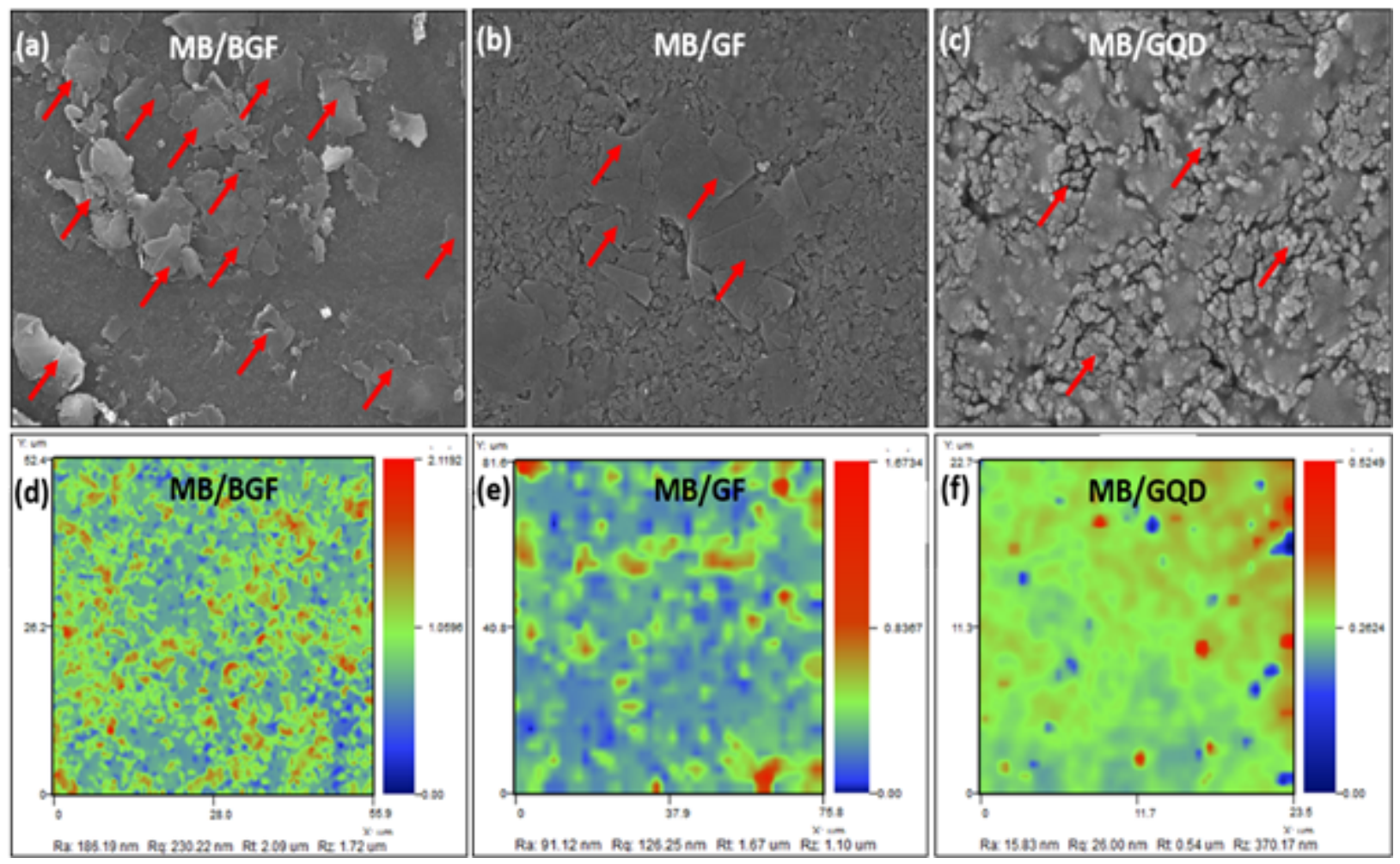

Figure 3 
(a) EDS spot profile of graphene shows $C$ peak and (b) EDS mapped image showing $C K$ series. Surface morphology of nanocomposite film, (a) MB/BGF at $5 \mu \mathrm{m}$ showing graphene flasks in bulk form in a nanocomposite film, (b) MB/GF nanocomposite film, and (c) MB/GQD film at a magnification of $5 \mu \mathrm{m}$, respectively. The 2D Nano profile of nanocomposite films, (d) MB/BGF, (e) MB/G, and (f) MB/GQD to confirm the surface roughness.

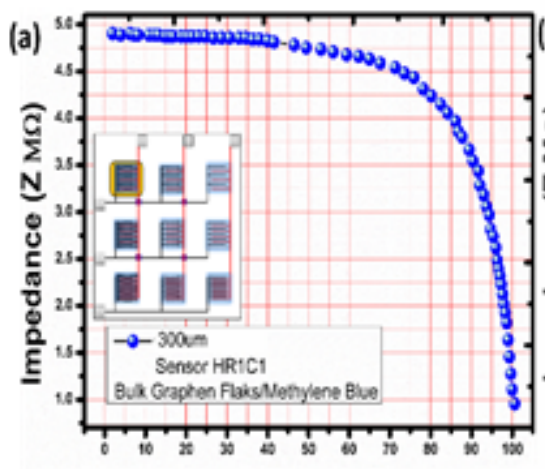

Relative Humidity (\%)

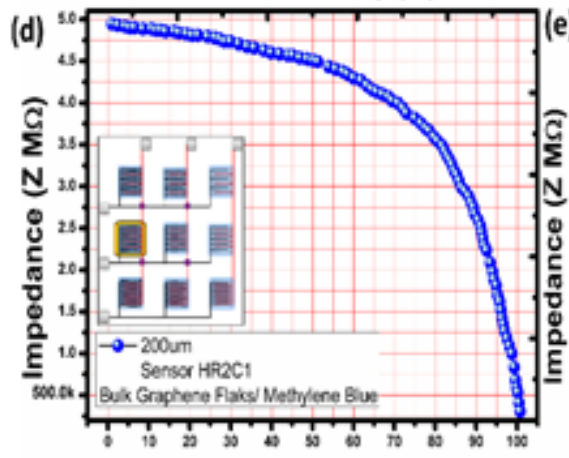

Relative Humidity (RH \%)

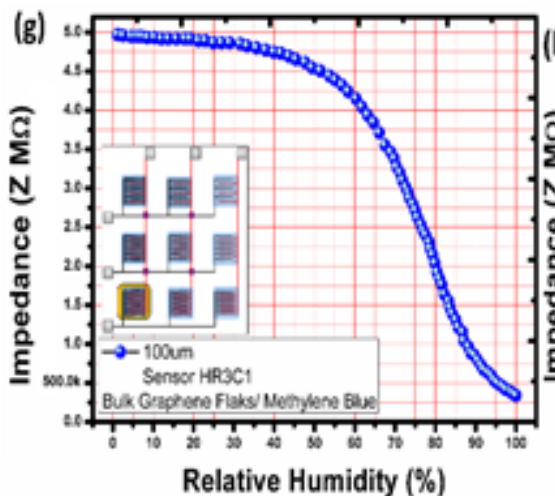

Relative Humidity (\%)

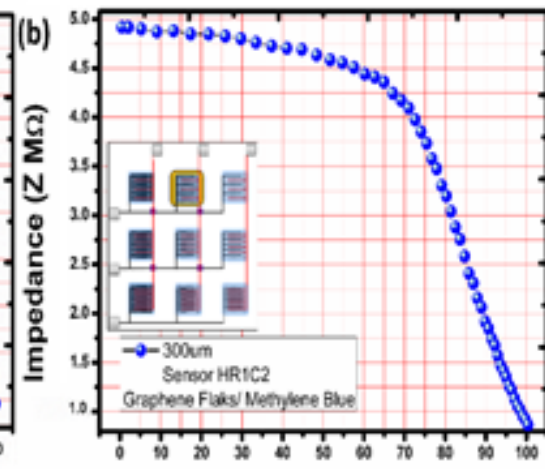

Relative Humidity (\%)

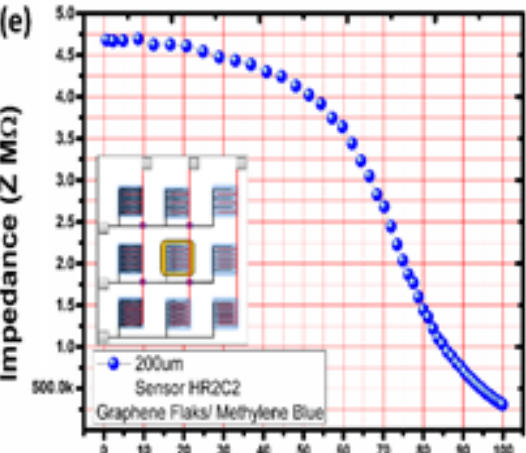

Relative Humidity (\%)

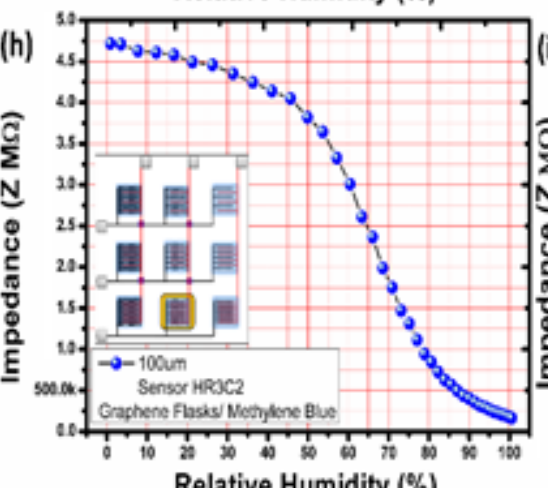

Relative Humidity (\%)

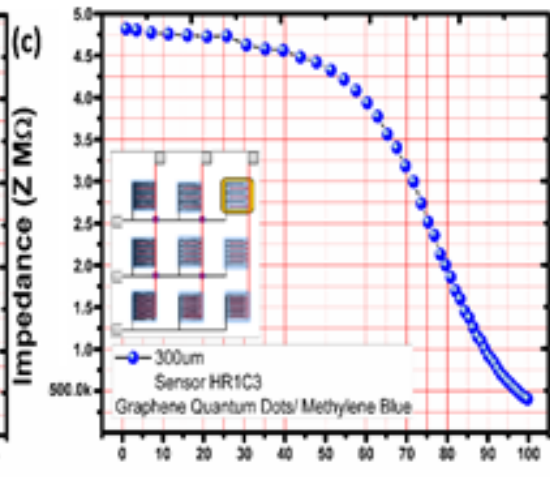

Relative Humidity (\%)

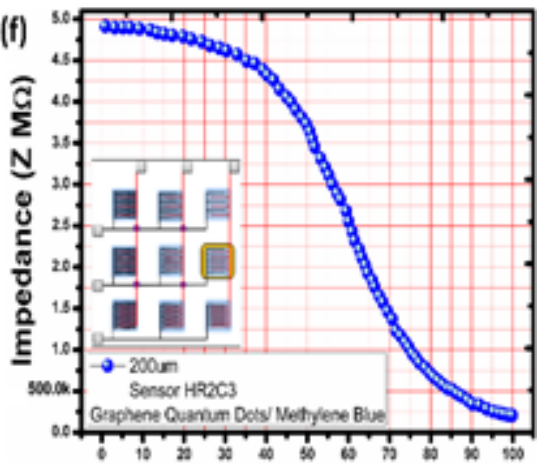

Relative Humidity (\%)

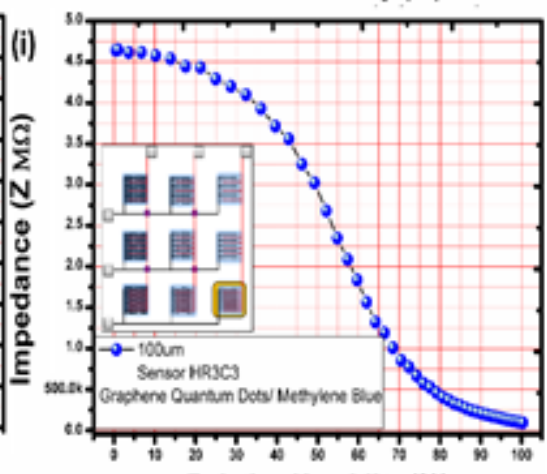

Relative Humidity $(\%)$

Figure 4

The $3 \times 3$ humidity sensing array showing sensors as following row 1 (a) HR1C1, (b) HR1C2, (c) HR1C3 with $300 \mu \mathrm{m}$. The row 2 contain following sensors (d) HR2C1 (e) HR2C2 (f) HR2C3 with $200 \mu \mathrm{m}$. The row 3 contain following sensors (d) HR3C1 (e) HR3C2 (f) HR3C3 with $100 \mu \mathrm{m}$. 
(a)
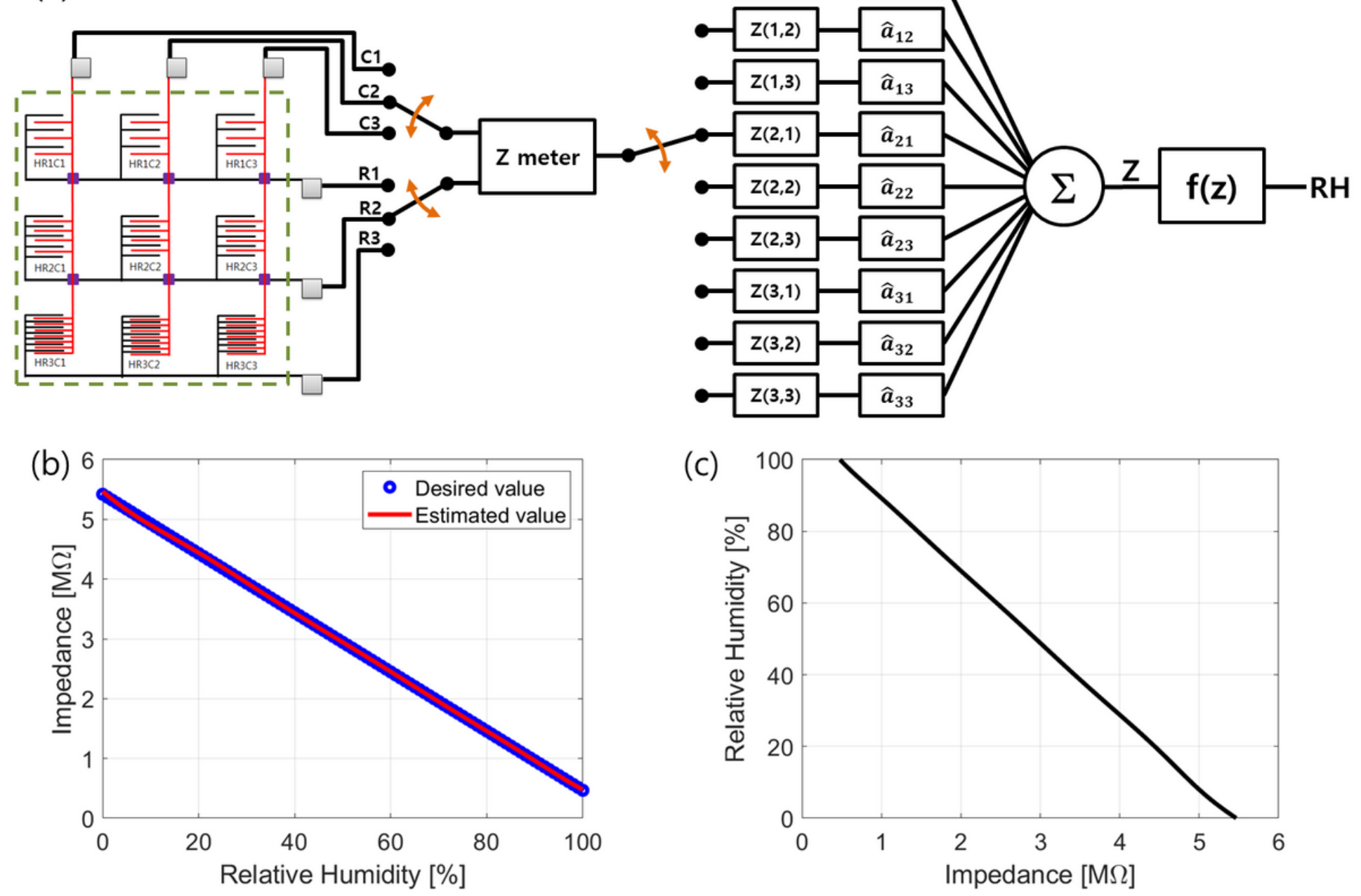

Figure 5

(a) Schematic diagram to find an RH value from the measured data of the proposed sensor array. (b) For all range linear function, comparison the ideal linear curve and the plotted estimated function by using the calculated estimate weight values (d) in Figure S10 of the supplementary information. (c) $f(z)$ to find relative humidity. 


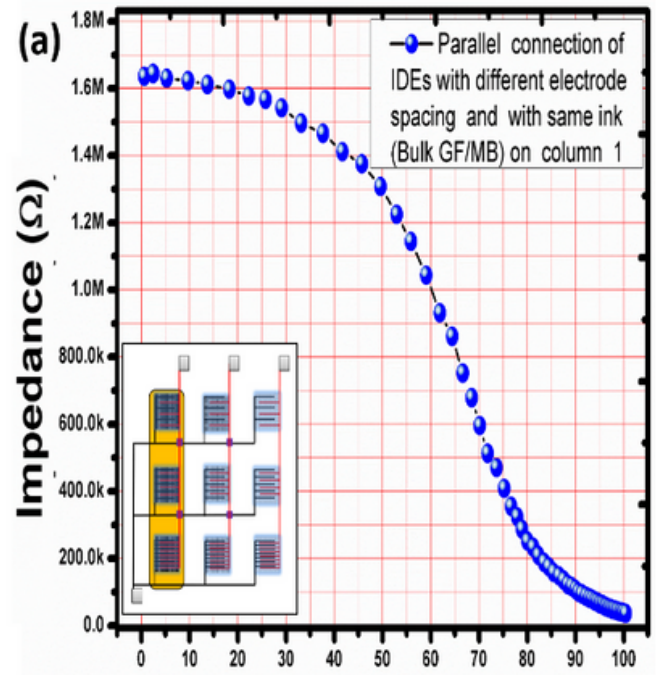

Relative Humidity $(\%)$

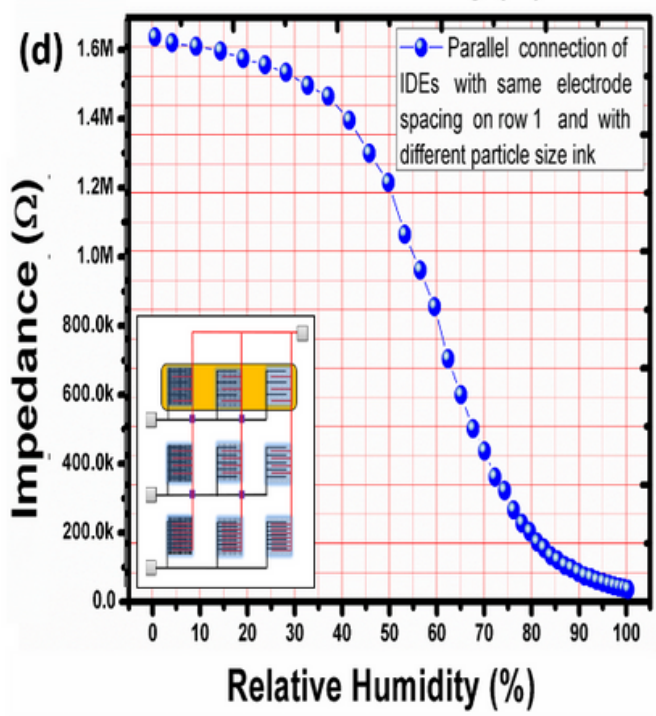

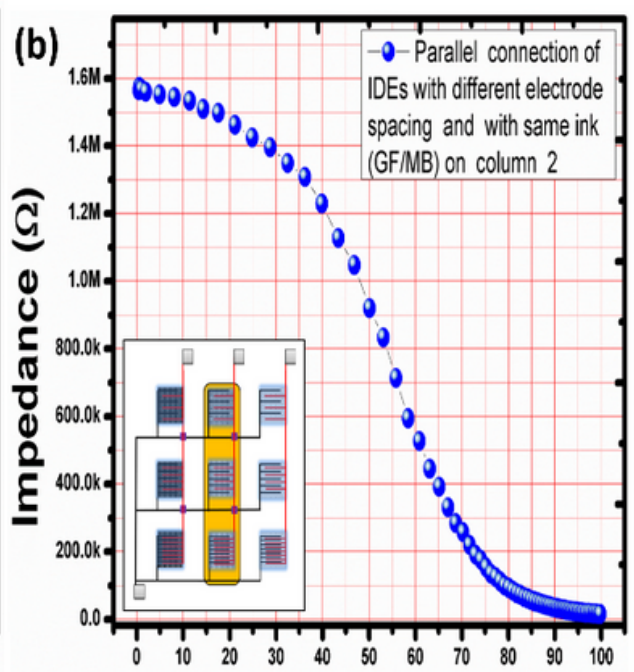

Relative Humidity $(\%)$

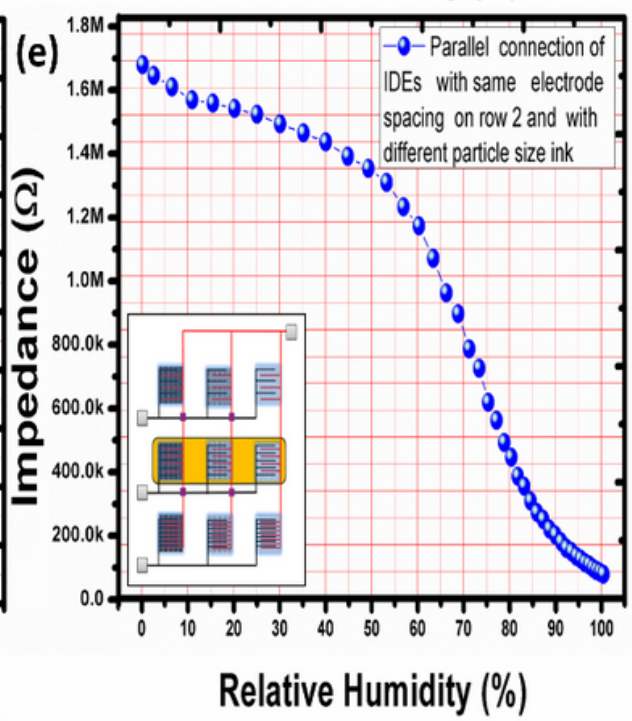

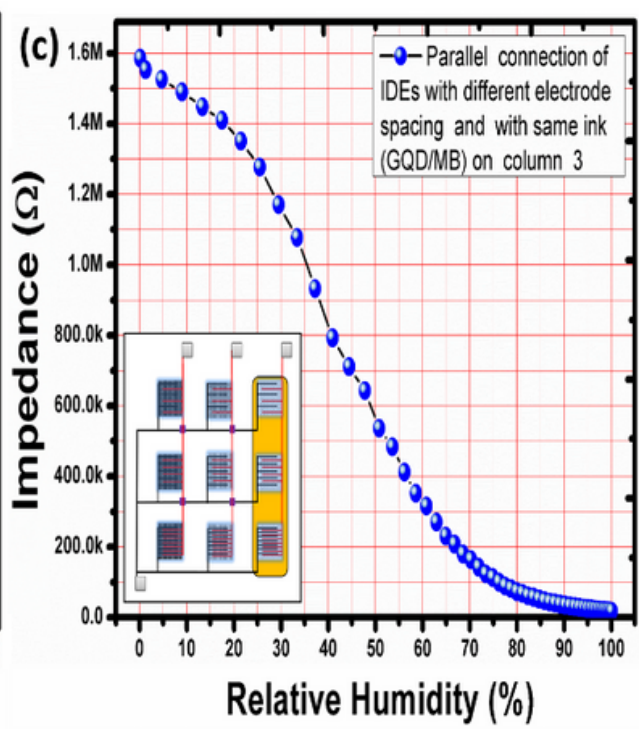

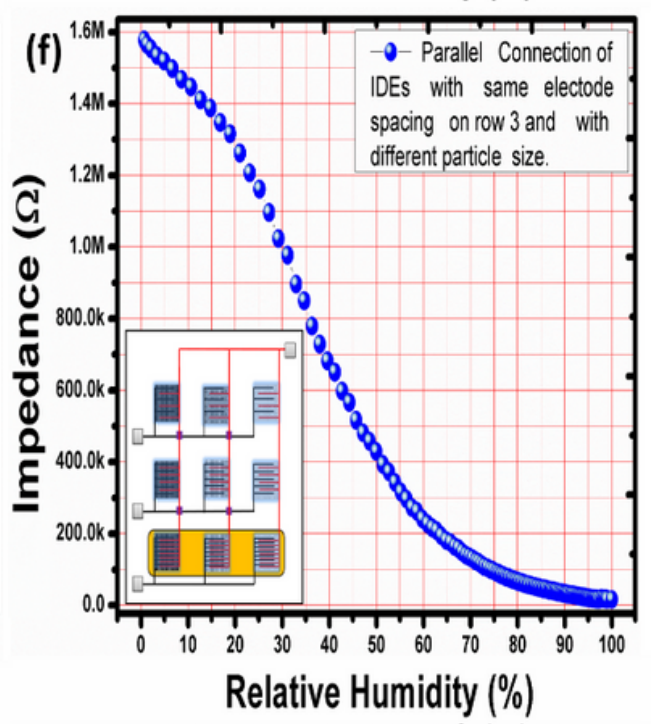

Figure 6

Impedance response of parallel combination of (a) column 1, (b) column 2 and (c) column 3, (d) row 1, (e) row 2 , and (f) row 3. 


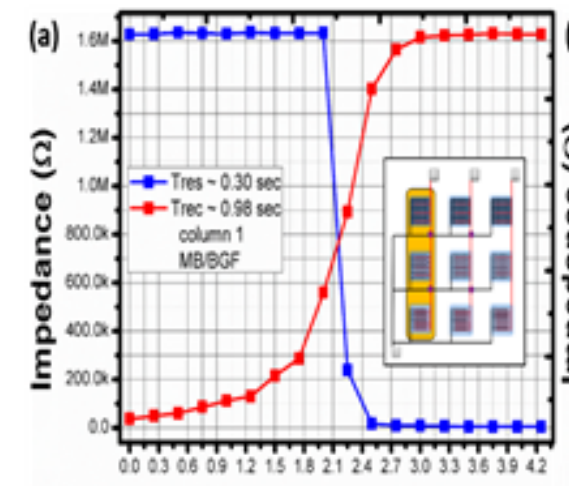

Time (sec)

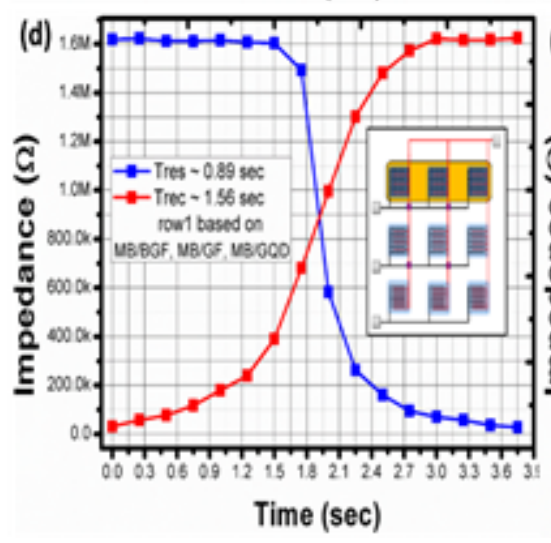

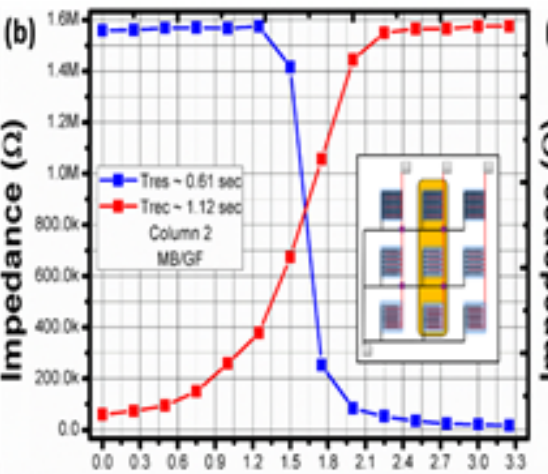

Time (sec)

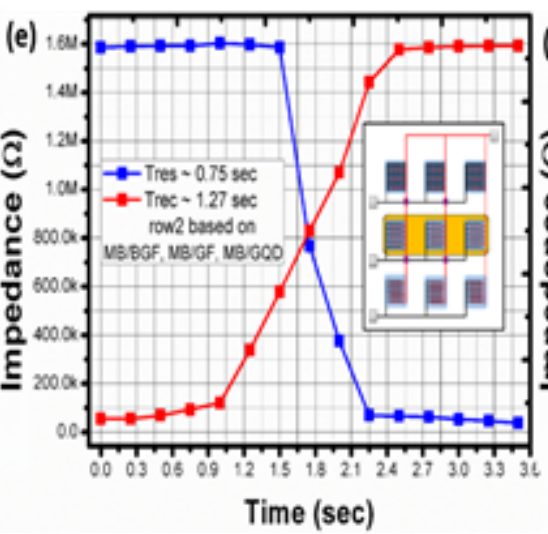

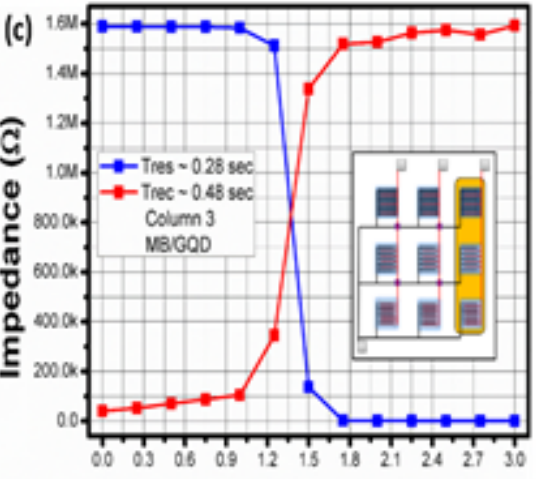

Time (sec)

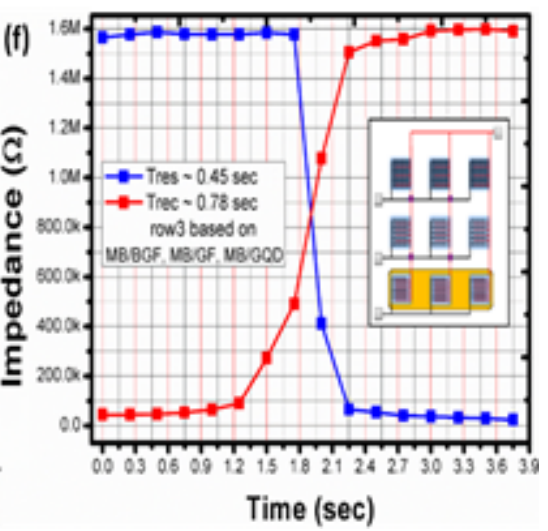

Figure 7

Transient response of (a) column 1, (b) column 2, (c) column 3, (d) row 1, (e) row 2, and (f) row 3.

\section{Supplementary Files}

This is a list of supplementary files associated with this preprint. Click to download.

- Supplementarylnformation.docx 